\title{
A prospective analysis of the preventability of adverse drug reactions reported in Sweden
}

Henrik Lövborg, Linda Ring Eriksson, Anna K Jonsson, Thomas Bradley and Staffan Hägg

\section{Linköping University Post Print}

N.B.: When citing this work, cite the original article.

The original publication is available at www.springerlink.com:

Henrik Lövborg, Linda Ring Eriksson, Anna K Jonsson, Thomas Bradley and Staffan Hägg, A prospective analysis of the preventability of adverse drug reactions reported in Sweden, 2012, European Journal of Clinical Pharmacology, (68), 8, 1183-1189.

http://dx.doi.org/10.1007/s00228-012-1237-2

Copyright: Springer Verlag (Germany)

http://www.springerlink.com/?MUD=MP

Postprint available at: Linköping University Electronic Press

http://urn.kb.se/resolve?urn=urn:nbn:se:liu:diva-79979 


\section{A prospective analysis of the preventability of adverse drug reactions}

\section{reported in Sweden.}

Running title: Preventability of adverse drug reactions

Authors: Henrik Lövborg* ${ }^{1}$, Linda Ring Eriksson ${ }^{1}$, Anna K Jönsson ${ }^{1}$, Thomas

Bradley, ${ }^{1}$ Staffan Hägg ${ }^{1,2}$.

1. Regional Pharmacovigilance Centre, Department of Clinical Pharmacology, Linköping University Hospital, S-581 85 Linköping, Sweden

2. Department of drug research/Clinical Pharmacology, Linköping University. S-581 85, Linköping, Sweden

*= corresponding author, Henrik.Lovborg@lio.se +46101034326

Conflict of interest, summary: Henrik Lövborg declares that his wife is an employee of a company (MEDAC) whose products are part of this study (as is the case for many other companies). We believe a statement is not necessary to publish since this type of study includes all drugs on the market, thereby limiting the risk of conflict of interest. 


\section{Abstract}

Purpose Adverse drug reactions (ADRs) are a major patient safety issue and a substantial proportion of ADRs are in fact preventable. The aim of this study was to describe the proportion and pattern of preventable ADRs in spontaneously reported suspected ADRs and to study the feasibility of using data from an ADR reporting system for this purpose.

Methods All reports of ADRs, except those where a vaccine was the suspected drug, submitted to the regional pharmacovigilance centre of south eastern Sweden between 2008 and 2009 were analysed. Causality between the suspected ADR and the medication was assessed using WHO criteria and preventability was assessed using Hallas criteria.

Results During the study period 1290 ADRs were received and 1255 were classified as having at least a possible causality between a reaction and a drug. Of these 172 (14\%) ADRs were considered preventable, 35 (20\%) were classified as definitely preventable and 137 $(80 \%)$ as possibly preventable. Of all preventable ADRs, $96(56 \%)$ were related to issues relating to prescribing, 35 (20\%) to administration of drugs and $41(24 \%)$ to clinical and laboratory monitoring of treatment. Warfarin, oxycodone and ioversol were the most common drugs with preventable ADRs.

Conclusions This study found that a substantial part of reported ADRs are preventable. Most of these are related to drug prescription suggesting that interventions aiming to reduce preventable ADRs should focus on this process. Moreover, systems for ADR reporting may be useful in the mission of reducing the unsafe use of drugs.

Keywords: adverse drug reaction, preventability, spontaneous reporting system 


\section{Introduction}

Adverse drug reactions (ADRs) are a major patient safety issue and may have significant consequences to the patients and health care systems, both in terms of medical outcome [1-3] and economic aspects [4,5]. ADRs occurring as a result of a medication error or substandard care could be considered preventable. The frequencies of preventable ADRs vary considerably in different studies. Most studies [6-10] indicate that a substantial proportion of ADRs are in fact preventable. This seems to be the case also for fatal ADRs [11].

Spontaneous reporting of suspected drug induced reactions is one of the main sources for detecting drug safety signals of marketed drugs. The strengths of these systems are numerous; they are already an established part of many health care systems and they monitor all patients and care settings. However, few efforts have been made to use these reports to extract information on how to prevent ADRs [12,13]. Therefore, this study was undertaken to investigate the proportion and pattern of preventable ADRs scrutinizing spontaneously reported suspected ADRs and to study the feasibility of using the Swedish ADR reporting system for this purpose.

\section{Methods}

In Sweden, healthcare professionals (doctors, nurses, dentists) are requested to report all serious or new suspected ADRs to the Medical Products Agency. ADRs were defined as all noxious and unintended responses to a medicinal product related to any dose. All reports are sent to one of six regional centres. At the regional centres information from the reports on the ADR, organ system affected, suspected drug, concomitant medication, age, gender, outcome and causality are stored in a national database (SWEDIS). In each report there may be more than one drug or ADR reported. Each combination of a drug and a reaction was regarded as 
one ADR in this study. Classification of drugs are based on the WHO Collaborating Centre for Drug Statistics Methodology International Anatomical Therapeutic Chemical (ATC) classification [14]. A modified national version of the World Health Organisation Adverse Reaction Terminology (WHO-ART) [15] was used to specify the type of reaction for all ADRs, the classification was based on body-system organ classes [16]. In each report causality was assessed by three experts with particular competence in clinical pharmacology and pharmacovigilance (SH clinical pharmacologist, $\mathrm{MD}, \mathrm{PhD} ; \mathrm{HL}$, pharmacist, $\mathrm{PhD} ; \mathrm{AKJ}$, pharmacist, $\mathrm{PhD}$ ) according to established WHO criteria [17]. Reactions were assessed as serious if leading to death, hospitalization or permanent injury and not serious if the reaction was transient and managed without the need for hospitalization. The preventability assessment was based on previously published criteria by Hallas [18], here summarized in table 1. In brief, each report was assessed by the same panel as for causality. Reports were classified as definitely preventable if the use of the drug was not in accordance with good medical practice (e.g. against contraindication, use despite known allergy, lack of compulsory monitoring etc.). Reports were classified as possibly preventable if an extra effort would have prevented the occurrence of the ADR (e.g. adjustment of dose, monitoring of vital signs etc.). The assessment was based on the information assumed to available to the treating physician at that time and a global evaluation of the narrative provided in the ADR report. If consensus in the expert panel was not reached the ADR was classified as not preventable. Remaining reports were either classified as not preventable or not evaluable.

After excluding ADRs where a vaccine was the suspected drug all remaining reported suspected ADRs submitted to the regional pharmacovigilance centre of South Eastern Sweden during 2008 and 2009 were scrutinized. Only reports where the causality between a reaction and a suspected drug was assessed as certain, probable or possible were finally included in the 
analyses. To the best of our knowledge there is no validated system for classification of the reason for preventability. We therefore modified a previously used grouping [12] of the reports, classifying the preventability as being related to prescribing, administration or monitoring, as described in table 2.

\section{Results}

During the study period 7322 reports (vaccine reports excluded) were submitted to the MPA in Sweden. The regional monitoring centre in South East Sweden received 702 of these reports $(9,6 \%)$. Healthcare professionals (doctors, nurses, dentists) working in open-care units submitted 159 reports (23\%) and healthcare professionals working in hospitals submitted 543 reports $(77 \%)$. The affected patients described in the reports were in average 58 years old (range 0-99). The reports concerned 423 (60\%) female patients, 274 (39\%) male patients and in five cases (1\%) information on sex were missing. In total 1290 ADRs were identified and $1255(97 \%)$ of these reactions were classified as having at least a possible causality with a suspected drug. Of the 1255 ADRs 662 (53\%) were classified as serious.

Of all ADRs included in the study, 172 (14\%) were considered preventable. Of these, 35 (20\%) were classified as definitely preventable and 137 (80\%) were classified as possibly preventable. Of the definitely preventable ADRs, 24 out of $35(69 \%)$ were classified as serious. The corresponding numbers of possibly preventable ADRs were 105 out of 137 (77\%) (table 2). Eight out of 37 ADRs (22\%) classified as contributing to the death of the patient were definitely or possibly preventable. Two ADRs $(0.2 \%)$ were not evaluable for preventability due to lack of crucial information, in one case information on dose was missing and in the other information on laboratory values was missing. 
Of all preventable ADRs, 96 (56\%) were related to issues relating to prescribing, 35 (20\%) to administration of drugs and $41(24 \%)$ to clinical and laboratory monitoring of treatment (table 2). In the case of prescription related preventable ADRs continuation or re-initiation of treatment despite obvious signs of an ADR, together with lack of dose-adjustment when combining with other drugs were the most common reasons for preventability. Other common reasons for preventability were that relevant precautions like age were not taken into consideration or that the drug was prescribed despite a known history of allergic reaction. For administration related preventable ADRs the main reason was erroneous administration of the drug by the patient. For preventable ADRs relating to suboptimal monitoring the main reasons were insufficient clinical monitoring (e.g. blood pressure) and insufficient monitoring of e.g. INR, electrolytes or liver function markers.

In table 3 we present the distribution of included ADRs in relation to the ATC-classification of the suspected drugs. High numbers of preventable ADRs were found for drugs within the ATC-codes N (nervous system, mainly N06 psychoanaleptics and N05 psycholeptics), C (cardiovascular system), B (blood and blood forming organs, mainly anticoagulants) and A (alimentary tract and metabolism) with 64, 29, 17 and 13 ADRs respectively. Low numbers of preventable ADRs were noted for ATC-codes $\mathrm{P}$ (antiparasitic products), R (respiratory system) and S (sensory organs). Warfarin was the most common individual drug with preventable ADRs followed by oxycodone and ioversol. The drugs with the highest number of preventable ADRs are listed in table 4 along with ADR diagnosis.

\section{Discussion}

This study showed that in spontaneously reported ADRs in Sweden a total of $14 \%$ was considered preventable, a figure which is in accordance with a similar study from France [12]. 
In that study, which was also based on spontaneously reported ADRs, a frequency of preventable ADRs of $17 \%$ was reported. However, in that study only ADRs resulting from inappropriate prescribing, defined as violation of the recommendations in the drug's Summary of Products Characteristics were included. Other studies, mainly based on medical record data and concerning hospitalized patients have reported proportions of preventable ADRs between 19 and $73 \%$ with a median of 35\% [10]. Since the cases in this study are based on spontaneous reports, which may be influenced by a skewed reporting of reactions, extrapolation to the overall population may be inappropriate.

The prescribing stage has been described as one of the most important in preventing ADR $[10,19]$. In accordance with this our study showed that $56 \%$ of all preventable ADRs were related to prescription. Continuation or reinitiation of treatment despite obvious signs of ADR is, according to our study, a major point to consider to reduce preventable ADRs. Establishing systems for treatment follow-up and awareness of signs of unwanted reactions is needed to reduce this factor. Increased efforts in pharmacological training, specifically focusing on ADR pharmacology, of nurses and doctors are likely to have beneficial effects. Another factor leading to a high number of preventable ADRs in our study was prescription of drugs without taking relevant precautions into consideration. It is reasonable to believe the also this factor could be reduced by educational efforts.

Prescription of a drug despite a known history of allergy to that drug has previously been reported to be a rather common cause of ADRs [20,21]. In our study most preventable ADRs related to allergic reactions was reported for contrast diagnostics for X-ray, which is a wellknown ADR for this class of drugs. These cases could have been prevented if available information of a previous allergic reaction, in the medical journal had been observed. 
Furthermore, in some cases the patients informed the health care personnel about previous allergic reactions retrospectively. Prevention of these cases could be based on better notes in medical records, routines or improved pharmacological prevention of reactions. However, the usefulness of pre-treatment in unselected patients has been shown to be small [22]. Interestingly no cases of preventable allergic reactions with anti-infective drugs (ATC J) were reported, despite a large number of reported ADRs of these reactions in conjunction with use of these drugs. Possibly this could be explained by a widespread awareness of this class of drugs when it comes to allergic reactions, along with routines for documentation and warnings in the medical records. It has been shown that this kind of notes in the medical records, despite their lack of validity, influence the choice of antibiotic used [23].

One factor often discussed in terms of preventable ADRs is drug-drug interactions. In our study this factor only accounted for $5 \%$ of the preventable ADRs. Most drug-drug interactions can be handled with dose adjustment or monitoring of laboratory values [24]. Also there is an increasing use of electronic medical records with automatic systems to detect some of these drug interactions that could potentially lead to an ADR. Such systems were available to the majority of the prescribers in the region during the period of our study. These different forms of clinical decision support systems has been shown to reduce drug-drug interaction related adverse drug events [25], possibly explaining the low frequency of interactions as a cause of preventable ADRs in our study.

Preventable ADR relating to administration of the drugs accounted for about $20 \%$ of all preventable ADRs. In our study we included erroneous administration by the patient as a cause of preventability, and this was the largest subgroup within administration. One limitation here is that we had incomplete data on e.g. the patients cognitive function and to 
what degree this was accounted for by the prescribing physician. However, we do believe that most of these cases could be prevented by better information by healthcare personnel or pharmacists about the drug and its use. Efforts to reduce errors of administration could include better information to both healthcare personnel and patients by improved packaging, packet leaflets and public awareness of drug related safety issues.

Lack of monitoring of drug treatment accounted for about $24 \%$ of all preventable ADRs. Other studies in the ambulatory setting show that this factor is important, with monitoring accounting for about half (range 22-70\%) of the preventable ADRs [6]. In our study many of these cases were related to monitoring of anticoagulant effect during warfarin treatment. Some of these cases included drug interactions with warfarin that is not considered contraindicated but should have warranted intensive monitoring of INR. It has been shown that drug-drug interactions is a major cause of warfarin bleeding complications and that about $12 \%$ of these were preventable through increased monitoring or awareness of interactions [26]. However, in the cases of warfarin interactions it is important to note that it also has been described that many bleeding complications occur within therapeutic INR range [27].

As shown in table 4 warfarin accounted for 12 preventable ADRs, representing $7 \%$ of all preventable ADRs. In the case of warfarin bleeding and increased INR were the most frequent ADR that could have been prevented, as described above possibly by increased monitoring. Anticoagulants have previously been shown to be a group of drugs which present a high proportion of preventable ADRs [26,28,29] and a study has indicated that use of warfarin also can serve as a predictor of preventable ADRs [30]. Oxycodone was the second most frequent drug associated with preventable ADRs. Reactions in these preventable ADRs were dose related, like respiratory disorders, nausea and fatigue, that could have been prevented by 
taking in to account combination with other drugs and increased monitoring of the patient. ADRs resulting from inappropriate or abrupt ending of treatment were not present in our material.

Among the preventable ADRs there were a higher proportion of serious ADRs compared to all reported ADRs. In our set of spontaneously reported cases 8 out of 37 ADRs (22\%) that were classified as contributing to the death of the patient were possibly or definitely preventable. Too high dose, both related to administration and prescription, was the most common reason for preventability in the fatal cases. A similar study in a population-based sample of 1574 deaths in Sweden, selected regardless of cause of death, analyzed cases of fatal ADRs. Three percent of all deaths in this population were considered possibly related to an ADR, and of these $14 \%$ were considered preventable according to the same criteria used in our study [11].

Some important limitations in our study need to be discussed. The spontaneous reports used in this study dose not include access to complete medical records, thereby limiting the possibility to extensively describe each case. However, the reports were still useful for analysis of preventability. Furthermore, spontaneous reporting of ADRs is by nature selective and only a small proportion of ADRs is reported $[31,32]$. It can be anticipated that preventable ADRs, i.e. medication error or substandard care, may be reported in an even lower rate. Definitely preventable ADRs are often due to direct errors or violation of recommendations [33] and this type of errors are probably reported via ADR systems to an even lower rate. However, the aim of this study was partly to see whether these reports of preventable ADRs do appear as reports in this already established system. 
Furthermore our study was limited to three county councils in the Southeastern region of Sweden. Regional differences may exist due to different practices and different access to health care institutions, both highly specialised and ambulatory care. A strength with our assessment of preventability is that a panel of experts were used and that it was performed prospectively. In addition, the use of spontaneous reports allows, in contrast to analysis of medical records, analysis of all kinds of prescriptions and drug use settings, i.e. primary care, hospital and emergency settings.

Several different instruments and processes may be used to assess preventability but there is no established gold standard for this assessment [34]. In this study we used a definition of preventability [18] based on consensus on whether the treatment was in accordance with present-day good medical practice and if an extra effort could have prevented the ADR. This way of determining preventability was chosen because it allows a global assessment of the whole treatment situation and excludes no reason for preventability as could be the case with e.g. predefined items in a scale. It will also easily allow one to add analysis of preventability to an established system for handling ADRs according to WHO criteria, as is the case in our study.

As with the definition of preventability, there is no widely accepted system for classification of the reason for preventability. Therefore we set up a number of reasons that appeared in our reports and divided these into subgroups, i.e. prescription, administration and monitoring. The classification system used in our study was related to the objectives of the study. A study focusing on preventable ADRs due to inappropriate prescribing have used a slightly different classification system [12]. 
The drug safety monitoring systems in use today mainly focus on unsafe drugs, rather than the unsafe use of drugs. Finding situations and activities relating to drug treatment and specific drugs where risks of errors occur is an important step to reduce the harm related to drug use. We believe that this study illustrate that it is possible to extract useful information on preventability of ADRs from spontaneous reporting systems as a mean to identify suitable interventions to reduce the unsafe use of drugs.

\section{Summary}

A substantial part of reported ADRs were found to be preventable in this study. The study indicates that a spontaneous reporting system may be used to identify preventable ADRs, and the reasons thereof, to better understand unsafe use of drugs. Although prescribing, administration and monitoring of medications may all be considered when it comes to planning interventions to reduce ADRs, this study found that preventable ADRs were most commonly related to the prescription of medications. These data support that interventions aiming to reduce preventable ADRs should focus on this process.

\section{Acknowledgement}

This study was funded by the County Council of Östergötland and the Swedish Medical Product Agency. 
Table 1

Assessment of preventability of ADRs.[18]

\begin{tabular}{|l|l|}
\hline Definitely preventable & $\begin{array}{l}\text { The drug event was due to a drug treatment procedure } \\
\text { inconsistent with present-day knowledge of good medical } \\
\text { practice or was clearly unrealistic, taking the known } \\
\text { circumstances into account. }\end{array}$ \\
\hline Possibly preventable & $\begin{array}{l}\text { The prescription was not erroneous but the drug event could } \\
\text { have been avoided by an effort exceeding the obligatory } \\
\text { demands. }\end{array}$ \\
\hline Not preventable & $\begin{array}{l}\text { The drug event could not have been avoided by any reasonable } \\
\text { means, or it was an unpredictable event in the course of a } \\
\text { treatment fully in accordance with good medical practice. }\end{array}$ \\
\hline Unevaluable & $\begin{array}{l}\text { The data for rating could not be obtained or the evidence was } \\
\text { conflicting. }\end{array}$ \\
\hline
\end{tabular}


Table 2

Classification of preventability of ADR.

\begin{tabular}{|c|c|c|c|c|c|c|}
\hline & & \multicolumn{2}{|c|}{ Definitely preventable $(\%)$} & \multicolumn{2}{|c|}{ Possibly preventable (\%) } & \multirow[t]{2}{*}{ Total $(\%)$} \\
\hline & & Non-serious & Serious & Non-serious & Serious & \\
\hline \multicolumn{7}{|l|}{ Prescribing } \\
\hline Indication & Lack of indication & $1(9)$ & 0 & 0 & 0 & $1(1)$ \\
\hline \multirow[t]{4}{*}{ Contraindication } & History of allergy & $2(18)$ & 0 & $4(13)$ & $5(5)$ & $11(6)$ \\
\hline & Contraindication & 0 & $1(4)$ & $1(3)$ & 0 & $2(1)$ \\
\hline & Combination of drugs should not be given together & 0 & 0 & 0 & $8(8)$ & $8(5)$ \\
\hline & $\begin{array}{l}\text { Combination of drug and food should not be given } \\
\text { together }\end{array}$ & 0 & 0 & 0 & $3(3)$ & $3(2)$ \\
\hline \multirow[t]{2}{*}{ Precautions } & Relevant precautions not taken into consideration & 0 & $2(8)$ & $2(6)$ & 13(12) & $17(10)$ \\
\hline & $\begin{array}{l}\text { Continuation or re-initiation of treatment after the } \\
\text { occurance of ADR }\end{array}$ & 0 & $4(17)$ & $5(16)$ & $14(13)$ & $23(13)$ \\
\hline \multirow[t]{3}{*}{ Dose not respected } & Dose schedule not respected & $2(18)$ & 0 & $4(13)$ & 0 & $6(3)$ \\
\hline & Dose not appropriate for renal function & 0 & 0 & 0 & $2(2)$ & $2(1)$ \\
\hline & $\begin{array}{l}\text { Dose not adjusted despite combination with other } \\
\text { drug }\end{array}$ & 0 & 0 & $5(16)$ & $18(17)$ & $23(13)$ \\
\hline Sum prescribing & & & & & & $96(56)$ \\
\hline
\end{tabular}

Table continues on next page! 
Table 2 continued

\begin{tabular}{|c|c|c|c|c|c|c|}
\hline & & \multicolumn{2}{|c|}{ Definitely preventable (\%) } & \multicolumn{2}{|c|}{ Possibly preventable (\%) } & \multirow[t]{2}{*}{ Total $(\%)$} \\
\hline Administration & & Non-serious & Serious & Non-serious & Serious & \\
\hline & Administration route & 0 & 0 & 0 & 0 & 0 \\
\hline & Erroneous administration -health care personel & $4(36)$ & $3(13)$ & 0 & $2(2)$ & $9(5)$ \\
\hline & Erroneous administration - patient & 0 & $14(58)$ & $3(9)$ & $9(9)$ & $26(15)$ \\
\hline Sum administration & & & & & & $35(20)$ \\
\hline \multicolumn{7}{|l|}{ Monitoring } \\
\hline \multirow[t]{2}{*}{ Clinical monitoring } & $\begin{array}{l}\text { Continued treatment despite lack of effect, } \\
\text { resulting in ADR }\end{array}$ & 0 & 0 & 0 & $4(4)$ & $4(2)$ \\
\hline & Insufficient clinical monitoring & 0 & 0 & $2(6)$ & $12(11)$ & $14(8)$ \\
\hline \multirow[t]{2}{*}{ Laboratory monitoring } & Insufficient clinical chemistry monitoring & $2(18)$ & 0 & $3(9)$ & $13(12)$ & $18(11)$ \\
\hline & Insufficient measuremnet of drug serum level & 0 & 0 & $3(9)$ & $2(2)$ & $5(3)$ \\
\hline Sum monitoring & & & & & & $41(24)$ \\
\hline & & & & & & \\
\hline \multicolumn{7}{|l|}{ Ending treatment } \\
\hline & $\begin{array}{l}\text { Abrupt termination despite risk of rebound or } \\
\text { withdrawal symptoms }\end{array}$ & 0 & 0 & 0 & 0 & 0 \\
\hline Sum & & $11(100)$ & $24(100)$ & $32(100)$ & $105(100)$ & $172(100)$ \\
\hline
\end{tabular}




\section{Table 3}

Spontaneously reported ADRs categorized after anatomic and therapeutic classification (WHO)

\begin{tabular}{|l|c|c|}
\hline & $\begin{array}{c}\text { Number of } \\
\text { reported ADR }\end{array}$ & Preventable ADR (\%) \\
\hline N Nervous system & 283 & $64(23)$ \\
\hline C Cardiovascular system & 200 & $29(15)$ \\
\hline B Blood and blood forming organs & 96 & $17(18)$ \\
\hline A Alimentary tract and metabolism & 71 & $13(18)$ \\
\hline J Antiinfectives for systemic use & 146 & $9(5)$ \\
\hline L Antineoplastic and immunomodulating agents & 138 & $9(7)$ \\
\hline V Various & 93 & $8(9)$ \\
\hline M Musculo-skeletal system & 85 & $7(8)$ \\
\hline G Genito-urinary system and sex hormones & 48 & $5(10)$ \\
\hline D Dermatologicals & 20 & $4(20)$ \\
\hline $\begin{array}{l}\text { H Systemic hormonal preparations, excluding sex hormones and } \\
\text { insulins }\end{array}$ & 33 & $3(9)$ \\
\hline R Respiratory system & 26 & $2(8)$ \\
\hline P Antiparasitic products, insecticides and repellents & 4 & $1(25)$ \\
\hline S Sensory organs & 12 & $1(8)$ \\
\hline Total & $\mathbf{1 2 5 5}$ & $\mathbf{1 7 2 ( 1 4 )}$ \\
\hline
\end{tabular}




\section{Table 4}

The drugs most frequently implicated in spontaneously reported ADRs considered preventable.

\begin{tabular}{|l|l|l|}
\hline Drug & Number of preventable ADR & ADR (n) \\
\hline Warfarin & 12 & $\begin{array}{l}\text { gastrointestinal bleeding (1), epistaxis (2), INR increased (5), petechiae (1), } \\
\text { haematuria (1), anemia (1), retroperitoneal bleeding (1) }\end{array}$ \\
\hline Oxycodone & 6 & vomiting (2), nausea (1), respiratory disorder (1), fatigue (1), constipation (1) \\
\hline Enalapril & 5 & urticaria (2), rash (1), pruritus (1), dyspnoea (1) \\
\hline Furosemide & 4 & renal failure (1), renal failure acute (1), anuria (1), angioedema (1) \\
\hline Metformin & 4 & $\begin{array}{l}\text { dehydration (1), hyperkalaemia (1), creatinine increased (1), hypotension orthostatic } \\
(1)\end{array}$ \\
\hline Tramadol & 4 & lactic acidosis (3), hyperkaelemia (1) \\
\hline
\end{tabular}




\section{References:}

1. Hartholt KA, van der Velde N, Looman CW, Panneman MJ, van Beeck EF, Patka P, van der Cammen TJ (2010) Adverse drug reactions related hospital admissions in persons aged 60 years and over, The Netherlands, 1981-2007: less rapid increase, different drugs. PLoS One 5 (11):e13977. doi:10.1371/journal.pone.0013977 2. Pirmohamed M, James S, Meakin S, Green C, Scott AK, Walley TJ, Farrar K, Park BK, Breckenridge AM (2004) Adverse drug reactions as cause of admission to hospital: prospective analysis of 18820 patients. BMJ 329 (7456):15-19.

doi:10.1136/bmj.329.7456.15

329/7456/15 [pii]

3. Davies EC, Green CF, Taylor S, Williamson PR, Mottram DR, Pirmohamed M (2009) Adverse drug reactions in hospital in-patients: a prospective analysis of 3695 patient-episodes. PLoS One 4 (2):e4439. doi:10.1371/journal.pone.0004439

4. Lundkvist J, Jonsson B (2004) Pharmacoeconomics of adverse drug reactions. Fundam Clin Pharmacol 18 (3):275-280. doi:10.1111/j.1472-8206.2004.00239.x FCP239 [pii]

5. Bates DW, Spell N, Cullen DJ, Burdick E, Laird N, Petersen LA, Small SD, Sweitzer BJ, Leape LL (1997) The costs of adverse drug events in hospitalized patients. Adverse Drug Events Prevention Study Group. JAMA 277 (4):307-311 6. Thomsen LA, Winterstein AG, Sondergaard B, Haugbolle LS, Melander A (2007) Systematic review of the incidence and characteristics of preventable adverse drug events in ambulatory care. Ann Pharmacother 41 (9):1411-1426. doi:aph.1H658 [pii] 10.1345/aph.1H658 
7. Soop M, Fryksmark U, Koster M, Haglund B (2009) The incidence of adverse events in Swedish hospitals: a retrospective medical record review study. Int J Qual Health Care 21 (4):285-291. doi:10.1093/intqhc/mzp025

8. Aranaz-Andres JM, Aibar-Remon C, Vitaller-Burillo J, Requena-Puche J, TerolGarcia E, Kelley E, Gea-Velazquez de Castro MT, the Ewg (2009) Impact and preventability of adverse events in Spanish public hospitals: results of the Spanish National Study of Adverse Events (ENEAS). Int J Qual Health Care 21 (16):408-414. doi:10.1093/intqhc/mzp047

9. Krahenbuhl-Melcher A, Schlienger R, Lampert M, Haschke M, Drewe J, Krahenbuhl S (2007) Drug-related problems in hospitals: a review of the recent literature. Drug Saf 30 (5):379-407. doi:3053 [pii]

10. Kanjanarat P, Winterstein AG, Johns TE, Hatton RC, Gonzalez-Rothi R, Segal R (2003) Nature of preventable adverse drug events in hospitals: a literature review. Am J Health Syst Pharm 60 (17):1750-1759

11. Jönsson AK, Hakkarainen KM, Spigset O, Druid H, Hiselius A, Hägg S (2009) Preventable drug related mortality in a Swedish population. Pharmacoepidemiol Drug Saf 19 (2):211-215. doi:10.1002/pds. 1890

12. Jonville-Bera AP, Saissi H, Bensouda-Grimaldi L, Beau-Salinas F, Cissoko H, Giraudeau B, Autret-Leca E (2009) Avoidability of Adverse Drug Reactions Spontaneously Reported to a French Regional Drug Monitoring Centre. Drug Saf 32 (5):429-440

13. Winterstein AG, Hatton RC, Gonzalez-Rothi R, Johns TE, Segal R (2002) Identifying clinically significant preventable adverse drug events through a hospital's database of adverse drug reaction reports. Am J Health Syst Pharm 59 (18):17421749 
14. WHO Collaborating Centre for Drug Statistics Methodology, Guidelines for ATC classification and DDD assignment. (2009).

15. World Healt Organisation Collaborating Centre for International Drug Monitoring. Adverse Reaction Terminology. (1991).

16. Lindquist M, Edwards IR (2001) The WHO Programme for International Drug Monitoring, its database, and the technical support of the Uppsala Monitoring Center. J Rheumatol 28 (5):1180-1187

17. Wester K, Jönsson A, Spigset O, Hägg S (2007) Spontaneously reported fatal suspected adverse drug reactions: a 10-year survey from Sweden. Pharmacoepidemiol Drug Saf 16 (2):173-180. doi:10.1002/pds.1263 18. Hallas J, Harvald B, Gram LF, Grodum E, Brosen K, Haghfelt T, Damsbo N (1990) Drug related hospital admissions: the role of definitions and intensity of data collection, and the possibility of prevention. J Intern Med 228 (2):83-90

19. Howard RL, Avery AJ, Howard PD, Partridge M (2003) Investigation into the reasons for preventable drug related admissions to a medical admissions unit: observational study. Qual Saf Health Care 12 (4):280-285

20. Jones TA, Como JA (2003) Assessment of medication errors that involved drug allergies at a university hospital. Pharmacotherapy 23 (7):855-860 21. Seeger JD, Kong SX, Schumock GT (1998) Characteristics associated with ability to prevent adverse drug reactions in hospitalized patients. Pharmacotherapy 18 (6):1284-1289

22. Tramer MR, von Elm E, Loubeyre P, Hauser C (2006) Pharmacological prevention of serious anaphylactic reactions due to iodinated contrast media: systematic review. BMJ 333 (7570):675. doi:bmj.38905.634132.AE [pii] 10.1136/bmj.38905.634132.AE 
23. Lutomski DM, Lafollette JA, Biaglow MA, Haglund LA (2008) Antibiotic allergies in the medical record: effect on drug selection and assessment of validity.

Pharmacotherapy 28 (11):1348-1353. doi:10.1592/phco.28.11.1348

10.1592/phco.28.11.1348 [pii]

24. Zwart-van Rijkom JE, Uijtendaal EV, ten Berg MJ, van Solinge WW, Egberts AC (2009) Frequency and nature of drug-drug interactions in a Dutch university hospital.

Br J Clin Pharmacol 68 (2):187-193. doi:BCP3443 [pii]

$10.1111 / j .1365-2125.2009 .03443 . x$

25. Bertsche T, Pfaff J, Schiller P, Kaltschmidt J, Pruszydlo MG, Stremmel W, Walter-Sack I, Haefeli WE, Encke J (2010) Prevention of adverse drug reactions in intensive care patients by personal intervention based on an electronic clinical decision support system. Intensive Care Med 36 (4):665-672. doi:10.1007/s00134010-1778-8

26. Jönsson AK, Spigset O, Jacobsson I, Hägg S (2007) Cerebral haemorrhage induced by warfarin - the influence of drug-drug interactions. Pharmacoepidemiol Drug Saf 16 (3):309-315. doi:10.1002/pds.1291

27. Kucher N, Connolly S, Beckman JA, Cheng LH, Tsilimingras KV, Fanikos J, Goldhaber SZ (2004) International normalized ratio increase before warfarinassociated hemorrhage: brief and subtle. Arch Intern Med 164 (19):2176-2179. doi:164/19/2176 [pii]

10.1001/archinte.164.19.2176

28. Ducharme MM, Boothby LA (2007) Analysis of adverse drug reactions for preventability. Int J Clin Pract 61 (1):157-161. doi:IJCP1130 [pii] $10.1111 / j .1742-1241.2006 .01130 . x$ 
29. Pearson TF, Pittman DG, Longley JM, Grapes ZT, Vigliotti DJ, Mullis SR (1994) Factors associated with preventable adverse drug reactions. Am J Hosp Pharm 51 (18):2268-2272

30. Hanlon JT, Pieper CF, Hajjar ER, Sloane RJ, Lindblad CI, Ruby CM, Schmader KE (2006) Incidence and predictors of all and preventable adverse drug reactions in frail elderly persons after hospital stay. J Gerontol A Biol Sci Med Sci 61 (5):511-515. doi:61/5/511 [pii]

31. Bäckstrom M, Mjörndal T, Dahlqvist R (2004) Under-reporting of serious adverse drug reactions in Sweden. Pharmacoepidemiol Drug Saf 13 (7):483-487. doi:10.1002/pds.962

32. Hazell L, Shakir SA (2006) Under-reporting of adverse drug reactions : a systematic review. Drug Saf 29 (5):385-396. doi:2953 [pii] 33. Ferner RE, Aronson JK (2010) Preventability of drug-related harms - part I: a systematic review. Drug Saf 33 (11):985-994. doi:2 [pii] $10.2165 / 11538270-000000000-00000$ 34. Hakkarainen K, Andersson Sundell K, Petzold M, Hägg S (2011) Methods for assessing preventability of adverse drug events - a systematic review. . Drug Saf In press 